\title{
LA LLORONA, LA CIGUANABA Y OTROS ESPECTROS FEMENINOS. CONFIGURACIÓN TIPOLÓGICA Y MOTIVOS LEGENDARIOS ${ }^{1}$
}

\author{
David Mañero Lozano \\ Universidad de Jaén \\ Jaén, España \\ dmanero@ujaen.es \\ RESUMEN / ABSTRACT
}

Este trabajo tiene como objeto, en primer lugar, analizar la configuración tipológica de la leyenda de la Llorona a partir del estudio comparado de los testimonios orales difundidos en distintas tradiciones de Hispanoamérica y EE. UU. Por otro lado, mediante el examen de los relatos sobre esta figura legendaria, se identifican los motivos folclóricos compartidos por esta y otras figuras espectrales. A este propósito, se examinan con especial detenimiento las correspondencias apreciables con la Ciguanaba, la Sucia y la Cegua, que desde el punto de vista tipológico consideramos como manifestaciones de un mismo personaje. Finalmente, se ofrece una aproximación a otros prototipos espectrales femeninos que presentan igualmente puntos de contacto con las leyendas de la Llorona y la Ciguanaba, con lo que se pretende deslindar los motivos asociados a las distintas mujeres fantasmales y sus rasgos específicos.

PALABRAs ClaVe: La Llorona, Ciguanaba, leyendas, tradición oral, mujeres fantasmales.

1 Este estudio se ha beneficiado del trabajo de documentación realizado en el marco del proyecto de I+D de Excelencia con referencia FFI2017-82344-P del Ministerio de Ciencia, Investigación y Universidades del Gobierno de España, financiado por la Agencia Estatal de Investigación (AEI) y al Fondo Europeo de Desarrollo Regional (FEDER). Agradezco las útiles observaciones aportadas por los revisores anónimos de la revista. 


\section{THE WEEPING WOMAN, THE CIGUANABA AND OTHER FEMALE GHOSTS. TYPOLOGICAL CONFIGURATION AND LEYENDARY MOTIVS}

The first purpose of this work is to analyze the typological configuration of the Weeping Woman legend through a comparative study of the oral testimonies disseminated in Latin America and USA. On the other hand, by examining the stories about this legendary figure, we try to identify the folk motifs shared with other spectral figures. For this purpose, we study with detail the correspondences between the Ciguanaba, the Dirty, and the Cegua, which we consider as manifestations of the same character from the typological point of view. Finally, we offer an approach to other female spectral prototypes that also have connections with the Weeping Woman and the Ciguanaba. Our objective is to define the motives associated to the different figures and their specific features.

KEYWORDS: Weeping Woman, Ciguanaba, legends, oral tradition, female ghosts.

Recepción: 13/03/2020

Aprobación: 23/12/2020

\section{ANTECEDENTES Y OBJETIVOS DE ESTE ESTUDIO}

La leyenda de la Llorona es, sin duda, una de las más extendidas y representativas de Hispanoamérica, además de haberse difundido gracias a los movimientos migratorios en EE. UU. y otros países (Kirtley 155) y de tener posibles antecedentes tanto en la tradición prehispánica como en la europea ${ }^{2}$.

Sin embargo, pese a la existencia de un prototipo narrativo perfectamente reconocible en todas las áreas de difusión de la leyenda, hay una considerable

2 Remito a la síntesis ofrecida por Badillo Gómez (92-94). Los motivos compartidos con la tradición prehispánica han sido considerados por González Manrique (544) y Granados (141), quien se ocupa también de la figura legendaria de la Xtabay, que sintetiza de este modo: "Xtabay aparece de noche, cerca de una ceiba, a veces en encrucijadas y generalmente solo a hombres. Se presenta bajo la forma de una mujer muy bella, en muchos de los casos una mestiza que posee una larga cabellera negra y viste un huipil, o bien se hace pasar por la novia o la mujer de la víctima. Una vez que el hombre es seducido, lo conduce a la selva, en donde lo arroja a un cenote, caverna o a una especie de cactus con espinas; en otras versiones, ahorca a los hombres y los deja colgados. Los hombres que logran escapar enferman de fiebre o enloquecen, no vuelven a ser normales" (Badillo Gómez 136). Kirtley (158-159) identifica versiones de esta leyenda en Alemania desde 1486, además de señalar otros paralelos europeos. De acuerdo con sus conclusiones, basada en una rigurosa comparación de los motivos folclóricos empleados en los distintos relatos, "German and Mexican legends are allotropes of a basically identical plot” (159). Por su parte, Aragón (3) documenta una variante africana de la leyenda introducida en América por los esclavos negros. 
variedad de desarrollos, que en ocasiones comparten motivos con los relatos protagonizados por otros seres fantasmales, como la Ciguanaba, la mujer de blanco o la autoestopista fantasma. Conviene, por tanto, realizar un estudio comparado de las distintas tradiciones para precisar sus elementos característicos. Así, me interesa analizar la configuración tipológica del ciclo legendario de la Llorona y, por otro lado, deslindar los motivos compartidos con otras figuras próximas a las que, no obstante, debe concedérseles una entidad propia.

De acuerdo con la caracterización general de la leyenda, la Llorona perdió o asesinó a sus hijos, tras lo cual su alma deambula lamentándose por la muerte de los niños. A estos acontecimientos iniciales, que conforman el primer segmento temporal del relato, se añade en un amplio conjunto de versiones la narración de los encuentros posteriores de la Llorona con individuos a quienes daña o atemoriza, con excepción de algunos casos en los que ella es agredida. En cuanto a la representación del personaje, los transmisores aluden de forma recurrente a una "hermosa mujer joven" (Pedrosa, Literatura oral 124) con el pelo largo, vestida de blanco (Guillén Ortiz 260) y "echándose agua o a veces lavando" (Martínez Reyes n. ${ }^{\circ} 430$ ). En algunas ocasiones, se la describe con otros rasgos compartidos por distintas mujeres fantasmales (como un ser casi intangible y etéreo, vestida de novia, etcétera) ${ }^{3}$.

En lo que respecta a la clasificación tipológica del relato, cabe señalar el empleo de motivos compartidos con el tipo narrativo "Death personified" ("La Muerte personificada") de Uther (ATU Z111), a lo que debe añadirse la presencia del motivo "The vanishing hitchhiker" ("El autoestopista evanescente") de Thompson (E 322.3.3.1). De cualquier modo, para una caracterización detallada y sistemática de los motivos desgranados en las distintas tradiciones, es de rigor acudir a la propuesta clasificatoria formulada por Boggs (3), más tarde completada por Robe (110-111), en la que se especifica una serie de motivos relacionados con estos cinco aspectos: I. Dónde aparece (a. En calles; b. Bosques; c. Al lado de ríos o arroyos); II. Cuándo aparece (a. A medianoche; b. En cualquier momento de la noche; c. De día);

\footnotetext{
$V$. $g r:$ "No se le ve la cara, no se ve nada. Se ve el bulto, se ven los brazos, el vestido largo y el pelo largo. Se ve que se levanta y camina por el viento" (Miller 100). Al igual que otros espectros femeninos, como la mujer de blanco (Martínez Reyes 328) y la Sucia (Martínez Reyes 434), la Llorona es representada en ocasiones con vestido de novia (Horcasitas 64; Sánchez Galicia 77). Para una descripción más detallada de la representación y caracterización del personaje, remito a Valdés (144-145).
} 
III. Forma con la que aparece (a. Con ropa corriente; b. Con una mortaja; c. No es vista, solo se escuchan sus lamentos; d. Como una bola de fuego; e. Vestida de blanco; f. Como una mujer con cara de animal); IV. Motivo por el que deambula (a. Busca a sus hijos perdidos; b. Busca a sus hijos después de haberlos ahogado; c. Está condenada a deambular después de muerta por haber asesinado a sus hijos); y V. Lo que hace a quienes se encuentra (a. Atrae a los hombres y los asesina en algún lugar apartado; b. Les pregunta si han visto a sus hijos; c. No les hace nada; d. Asusta a quienes la siguen) ${ }^{4}$.

En cuanto a los tipos folclóricos en los que se ramifica la leyenda, según la propuesta de Butterworth y Horcasitas (221-223) -quienes se ocuparon de analizar un repertorio de 120 versiones de distintas procedencias mexicanas-, cabe distinguir tres modelos narrativos primigenios: 1) Una joven indígena abandonada por su amante decide ahogar a sus hijos ilegítimos en un río. Tras su muerte, su espectro se aparece durante la noche lamentándose por las calles, cerca de las aguas, con una apariencia muy atractiva, pelo suelto y un largo vestido blanco; 2) Una mujer hermosa vestida de blanco y con el cabello largo atrae hasta lugares peligrosos a los hombres durante la noche, quienes aparecen muertos al día siguiente; y 3) Una narración engarzada de los dos tipos anteriores.

En esta última propuesta clasificatoria, es llamativo el desinterés por la riqueza de motivos y variantes narrativas apreciables en la tradición moderna. En efecto, con independencia del grado de fiabilidad que le concedamos a esta reconstrucción de las secuencias narrativas supuestamente empleadas en las versiones primigenias del relato, los autores no analizan su posterior desarrollo en las distintas áreas de difusión, cuestión que es necesario abordar asimismo desde un punto de vista tipológico.

Por otro lado, los especialistas en relatos legendarios de otras áreas hispánicas ofrecen descripciones que se contradicen en parte con estas observaciones referidas a la tradición mexicana. De este modo, Martínez Reyes -a quien debemos uno de los más valiosos repertorios de leyendas de Centroamérica, dedicado a la tradición hondureña- diferencia entre el modelo de "la mujer sufriente, dolorida, espectral (como la Llorona); y la mujer que causa dolor, agresiva, violenta con los hombres (como la Sucia, la Ciguanaba, la Cegua, la Taconuda y otras que forman parte de nuestro corpus)" (583), lo que entra

$4 \quad$ La traducción es mía. En concreto, los motivos añadidos por Robe sobre el esquema de Boggs son los rotulados en IIId, IIIe, IIIf y Vd. 
en contradicción con las acciones criminales a las que se refiere el tipo 2 de Butterworth y Horcasitas. Por su parte, en referencia a la tradición de Costa Rica, autores como Lizano consideran que "la Cegua, en Honduras y la Ciguanaba de El Salvador, corresponden más bien a nuestra Llorona" (106), apreciación que acrecienta aún más la confusión. De acuerdo con estas interpretaciones críticas, la figura de la Llorona es descrita mediante rasgos coincidentes con los de otros espectros femeninos como la Ciguanaba, que a su vez se considera distinta o equivalente, según los casos, de la Sucia o de la Cegua. Es necesario, por tanto, revisar en detalle los motivos específicos y compartidos por las distintas figuras, además de determinar en qué casos es pertinente considerarlas como manifestaciones con entidad propia y en cuáles debemos valorarlas como simples variantes de una misma figura aludida con distintos nombres o atributos folclóricos.

Dadas las características de relatos como el de la Llorona, su descripción tipológica nos obliga a atender tanto a la variedad apreciable en las distintas áreas geográficas como a los distintos motivos y variantes narrativas, objetivo este último que fue abordado ejemplarmente por Badillo Gámez a partir de siete versiones sobre la Llorona recogidas en tres comunidades de Puebla (México). En particular, la autora distingue tres tipos narrativos en los que integra las siete muestras estudiadas: 1) una mujer queda embarazada de un hombre que la abandona y mata a sus hijos, convirtiéndose en alma en pena; 2) una mujer pierde accidentalmente a sus hijos y desde entonces su alma vaga en pena buscándolos; y 3) las Lloronas seducen y matan a los hombres (Badillo Gámez 102).

Sin embargo, el análisis de un repertorio más amplio y de distintas procedencias geográficas nos permite observar cómo algunas de las muestras, que la estudiosa considera como variantes, presentan una secuencia de motivos idéntica a otras versiones, lo que nos lleva a valorarlas como tipos folclóricos independientes en lugar de variantes. Debe señalarse también, según lo esperable debido al reducido número de muestras manejadas, la existencia de otros tipos no representados en el mencionado repertorio. A partir de estas premisas, me propongo identificar, en primer lugar, los principales tipos narrativos asociados al relato de la Llorona en las principales áreas de difusión de la tradición oral hispánica. Dada la amplitud de este abordaje comparativo, en el que están implicados lugares muy diversos en cuanto a su configuración étnica y cultural, conviene explicitar la procedencia de los testimonios examinados. La mayor parte de los trabajos de recopilación a los que he accedido proceden de México, con predominio de las manifestaciones 
transmitidas en Veracruz, Puebla, Estado de México y Ciudad de México. Son también significativas las muestras recopiladas en Honduras y Nicaragua, a lo que se añaden algunas noticias muy residuales de Costa Rica y Puerto Rico ${ }^{5}$. Unido a esto, he tenido en consideración algunos testimonios de EE. UU., aunque debe destacarse que se trata de versiones documentadas en estados colindantes con México, como Nuevo México, Arizona y California, con lo que la presencia de la cultura mexicana aporta una base de comparación representativa y coherente a pesar de la vastedad del territorio comprendido ${ }^{6}$.

\section{CARACTERIZACIÓN TIPOLÓGICA DEL RELATO DE LA LLORONA}

A continuación, me ocuparé de identificar los distintos tipos narrativos asociados al primer segmento temporal del relato (al que he asignado la letra A). Contamos, en primer lugar, con versiones en las que la pérdida de los hijos se debe a causas accidentales. Así, un informante hondureño, procedente de Morolica (Choluteca), relató la muerte de la Llorona y de sus hijos en un accidente de tráfico: "Hay un sitio que lo llaman la cuesta de la Virgen, que dicen que ahí sale la Llorona, ¿no?, una mujer que [...] se accidentaron ahí y..., y murieron todos. Sale llorando la mujer buscando a sus niños" (Mañero Lozano 542n). A este tipo narrativo, que etiquetaré como A1, puede asociarse asimismo la versión recogida por Badillo Gámez (97-98) en Santa Cruz (Puebla, México) a la que titula "La llorona de Xochimilco". Esta muestra comienza con una descripción de la procedencia y ocupación de la Llorona, caracterizada como vendedora de flores en una de las balsas de los canales de Xochimilco. Al regresar de trabajar, la mujer ve arder su casa y

5 En el caso de Costa Rica, Lizano (105-106) da una noticia indirecta que atestigua el conocimiento de la leyenda en el país. Por lo demás, identifica el relato como "nuestra Llorona", si bien considera que "es de fuente extranjera" y se refiere a las correspondencias con el alma de la Malinche (106-107). En cuanto a Puerto Rico, tan solo he accedido al testimonio de una mujer de la localidad de San Germán, quien sencillamente afirmó: "Sí, la llorona es la que va por los caminos llorando porque ha perdido a sus hijos. Sí se conoce, se conoce perfectamente. Vestidita de blanco y llorando porque perdió a sus hijos" (Mañero Lozano 0769n).

6 A comienzos del siglo XX, Espinosa (401) ya mencionó la presencia de esta leyenda en Santa Fe (Nuevo México), a lo que se suman otros testimonios como los de Leddy (" $\mathrm{La}$ Llorona in Southern") y Hawes. 
baja con precipitación de la balsa, olvidándose de llevar consigo a sus hijos, a quienes se lleva la corriente. De igual modo que en la versión hondureña, los hijos mueren por accidente en su medio de transporte habitual. En otra versión, procedente del Distrito Central de Honduras, asimilable al tipo A1, se narra también la muerte accidental de la familia: "se la llevó la crecida de un río. Ella iba cruzando con su bebé en brazos y con otro niño agarradito de la mano. Y ahí quedó penando, llorando y buscando a sus hijos" (Martínez Reyes n. ${ }^{\circ} 430$ ).

Por otra parte, Badillo Gámez (99) informa de una muestra (n. $\left.{ }^{\circ} 4\right)$ procedente de Huatlatlauca (Puebla, México), en la que el esposo de la Llorona descuartiza a sus hijos y los arroja al mar, donde la mujer encuentra los restos y comienza a lamentarse ${ }^{7}$. Esta secuencia narrativa, que podría etiquetarse como tipo A2, se corresponde con lo relatado en la siguiente muestra, ambientada en época colonial: "Sucedió en la época del virreinato, en la ciudad de México. Se trataba de un matrimonio, en el cual el esposo era un individuo bastante malo, sanguinario. Mató a los hijos suyos, y la madre en desesperación al poco tiempo después murió" (Horcasitas Pimentel 45). Como variante de este mismo tipo, en otra muestra hondureña, la Llorona pierde a los hijos a causa de un individuo que se los arrebata y golpea mortalmente a la mujer: "Por ahí cuentan que había una mujer embarazada que estaba muy ilusionada con su bebé. Y como a los diez días de nacido, un hombre se metió en el cuarto de la mujer, le golpeó la cabeza y se robó al bebé. Entonces dicen que esa mujer se murió del golpe, y que su alma se quedó buscando a su bebé" (Martínez Reyes n. ${ }^{\circ}$ 431).

En otras versiones, es la propia Llorona quien, tras sufrir un despecho amoroso, da muerte a sus hijos, generalmente arrojándolos a un río o cascada. Así, por ejemplo, en la tradición de Nicaragua se relata que la mujer, después de ser abandonada por un extranjero de quien queda embarazada, "en un ataque de histeria, lanzó a sus hijos en una cascada, matándolos" y a continuación decide suicidarse (Pedrosa, Literatura oral n. ${ }^{0}$ 124). Los motivos que se enlazan coinciden con una de las versiones registradas por Badillo Gámez

\footnotetext{
A propósito de las versiones en las que la Llorona no mata a sus hijos, Badillo Gámez formula una interesante conclusión: "Esto da cuenta, de alguna manera, de que la representación que de esta figura están haciendo las comunidades se está reconfigurando. [...] la carga negativa hacia el personaje si no desaparece, sí disminuye en tanto que caben otras posibilidades de acción: la de perder a sus hijos por descuido y la de que los hijos fueron víctimas del marido de la Llorona" (102).
} 
(98-99), a la que da el título genérico de "La Llorona". En esta, una mujer abandonada por "un señor capitán" mata de modo muy sangriento al hijo que había tenido con este y después se arroja por un barranco con la cabeza de su hijo en la mano. El empleo de una misma secuencia de motivos nos permite sostener la existencia de un tipo independiente (A3). En otra de las muestras nicaragüenses, el detonante de la tragedia es la mala convivencia de la mujer con un marido que "la trataba mal, porque él no quería a sus hijos", por lo que "decidió ahogar a los niños en la quebrada ['arroyo o riachuelo']", lo que a su vez desencadena que el marido la asesine (Pedrosa, Literatura oral n..$\left.^{\circ} 125\right)$. El desenlace difiere, por tanto, respecto del motivo del suicidio antes descrito. No he encontrado, sin embargo, otras versiones en las que la mujer sea asesinada por haber dado muerte a los hijos, por lo que, al menos de forma provisional, cabe clasificar esta versión como una variante de A3 en lugar de un nuevo tipo.

En otros casos, se documentan relatos que aluden sencillamente al motivo del abandono de los niños por parte de la madre: "una mujer que primero no quiso a sus hijos y los regaló y los dio, vamos, los tiró a la calle, los tiró, y pasó el tiempo, se hizo vieja y Dios la castigó y le dijo que nunca iba a morir" (Guillén Ortiz 257). Este relato cuenta también con variantes ubicadas en los ríos, como esta de Zempoala (Veracruz, México): "Esta fue una mujer de mundo y se pervirtió a ser mala... por ser este... siempre libre botó su criatura... al río. Pero al mismo tiempo siguió penando. Murió y siguió penando ella onde buscaba su criatura en el... onde la había tirado" (Robe n. ${ }^{\circ}$ 46); o esta otra del Distrito Central de Honduras: "Mi abuela contaba que la Llorona fue una mujer que ahogó a su bebé en un momento de locura. Dicen que ella después se mató, y que ahora aparece en los lugares donde hay agua, como en ríos o en pilas" (Martínez Reyes n. ${ }^{\circ}$ 432). La selección de motivos, que podemos tipificar como A4, se corresponde en términos generales con la versión denominada "La Llorona y los ríos" por Badillo Gámez (96-97), procedente de Molcaxac (Puebla, México), si bien en esta se atribuye a una decisión de Dios que la mujer se convierta en alma en pena, a la que se da una oportunidad para salvarse: "Hasta que traigas todos tus hijos, te perdono. Vete a vagar, vete a buscarlos, a vagar por el mundo a donde los echaste, donde los mataste, los ahogaste, y cuando los juntes todos, entonces ya te perdono" (97).

Es de notar que muchas de las versiones, como casi todas las mencionadas hasta el momento, se limitan a narrar la primera secuencia temporal de la leyenda (A). Existe, sin embargo, una amplia tradición de relatos que se centran 
en los encuentros de la Llorona con otros individuos a los que atemoriza, daña o mata (segmento B). Esta circunstancia ratifica la observación de Kirtley, no aplicable a los relatos antes comentados, cuando afirma que en las narraciones sobre la Llorona es la víctima de la mujer quien protagoniza la acción, en lugar de focalizarse la atención en el personaje de la Llorona (156). A pesar de esta clara diferencia en el punto de vista narrativo, las relaciones de causalidad apreciables entre estas dos secuencias temporales nos explican su asimilación dentro de un mismo ciclo legendario por parte de los transmisores del relato ${ }^{8}$.

En relación con la secuencia temporal B, en Badillo Gámez (100-102) se documentan tres versiones recogidas en comunidades de Puebla (México) que transmiten un tipo narrativo bien definido: un hombre es atraído por la Llorona, quien provoca que su víctima se desbarranque, o fallezca ahogada en otras muestras: "A veces lleva a los hombres hasta una barranca, y he oído también que a veces los ahoga en los lagos" (Horcasitas Pimentel 66). Dentro de este tipo, al que denominaré B1, podemos incluir otras versiones en las que el espectro atrae a algún individuo y le produce después algún tipo de espanto o daño físico, o sencillamente produce perturbación o espanto mediante su aparición momentánea, como en esta muestra de Arizona: "When they see her she is weeping. They have seen her out in the Woods near Patagonia [Santa Cruz, Arizona] and has disappeared as suddenly as she appears" (Leddy, "La Llorona in Southern" 273). En palabras de esta misma investigadora: "the general impression concerning a visit from La Llorona is one of danger, of overwhelming fear, although the victims are not always affected fatally" (Leddy, "La Llorona Again” 365).

Entre las variantes de este tipo, cabe mencionar los relatos en los que la Llorona tiene como víctimas a los niños, como es el caso de esta muestra de Northridge (California, EE. UU.) obtenida por Bess Lomax Hawes en 1962, en la que se produce un engarce de los tipos A3 + B1:

\footnotetext{
Para un interesante análisis de las relaciones de causalidad y paralelismos de motivos que propician las conexiones entre las dos secuencias temporales, véase Kearney (203-205), quien concluye: "Thus the circular relation of the aggressive act, muina ['enojo'], and aggressive act closes, for the victim of La Llorona is really, within the logic of the system, the same dominant male who, because of his own muina and desire for revenge, betrayed his wife in the beginning" (205). Se trata, en cualquier caso, de una explicación solo aplicable a una parte de las versiones que circulan en la tradición.
} 
Some of the Indian women killed their children in order to keep the Spaniards from taking them. La Llorona is one such woman. She now is searching constantly for her children, whose faces she sees in all children. She kills the children to be united with her own again (159).

Se documenta, por otro lado, un tipo narrativo diferenciado que podríamos tipificar como B2. En este, es el espectro quien padece las consecuencias negativas del encuentro con los vivos, con independencia de que las agresiones sufridas por la Llorona resulten frustradas (Caballero 201) o logren extinguir definitivamente su espíritu:

Recorría las calles del pueblo y luego se dirigía a un lago y allí se desvestía y bailaba. Una noche pasó cerca de una iglesia gritando: “¡Ay, mis hijos! ¡Ay, mis hijos!”. El sacerdote salió y le dijo: "Hija mía, acércate". Cuando ella se acercó, le echó agua bendita, y ella quedó convertida en piedra (189).

Algunas versiones asociadas a la secuencia temporal B incorporan motivos propagados por otros relatos legendarios, como sucede en aquellas muestras en las que se describe de modo contradictorio la distancia a la que se encuentra un peligro y la proximidad con la que la víctima lo percibe. Según indica Guillén Ortiz (143-144), en la tradición de Coatepec (Veracruz, México), el llanto del personaje se percibe en la lejanía cuando está cerca $\mathrm{y}$, por el contrario, se oye más cercano cuanto más alejada se encuentra ${ }^{9}$. Este motivo está representado en otras tradiciones como la guatemalteca (Pedrosa, Cuentos 55) y la hondureña, donde lo encontramos aplicado al personaje de la Taconuda (Martínez Reyes $n$. $^{\circ}$ 109). Se trata de circunstancias que provocan desorientación en las víctimas y contribuyen a incrementar la sensación de miedo.

Otro de los motivos folclóricos a los que se recurre en la secuencia temporal B es la aparición de la Llorona con forma de tizón o bola de fuego (Robe n. ${ }^{\circ}$ 49), imagen también asociada a otras apariciones espectrales (Martínez Reyes n. ${ }^{\circ}$ 273). Es asimismo recurrente la transformación de la cara de la mujer en calavera descarnada o en cabeza de mula cuando es alcanzada

$9 \quad$ Sobre la casuística de percepciones sensoriales, tanto visuales como auditivas, con las que los transmisores describen a la Llorona, véase la síntesis ofrecida en Valdés (141-144). 
por las víctimas a las que atrae. Así se describe esto último en otro relato de Veracruz: "dice que cuando voltea se le ve esa trompa de mula, la cara de mula. Que sí se ve muy bonita. Él dice que la vio que se ve muy bonita, así con su vestido largo de novia, así con su colota bien larga, pero dice que cuando voltea, ¡ay no, ay no!" (Guillén Ortiz 259-260), al igual que en otras de las versiones veracruzanas documentadas (Robe n. ${ }^{\circ} 46,47$ y 48). El mismo motivo aparece asociado a la figura de la Ciguanaba en la tradición guatemalteca (Lara Figueroa 82).

En la tradición hondureña, el personaje puede adoptar la identidad de la novia del individuo con el que se encuentra (Martínez Reyes n. ${ }^{\circ} 320$ ), motivo recurrente en los relatos sobre la Sucia (n. ${ }^{\circ} 296$ y n. $\left.{ }^{\circ} 298\right)$ de los que me ocuparé más adelante. También parece extraído de otros relatos legendarios, en los que habré asimismo de detenerme, donde se presenta el motivo de la mujer fantasma que se sube a los automóviles de quienes circulan por los lugares donde pena su alma. Así, un informante hondureño que transmitió un relato sobre la Llorona apostilló: "Eso se cuenta, e incluso hay algunos que hasta la han subido al coche, pero eso no. Son como leyendas que he escuchado yo por ahí" (Mañero Lozano 542n). Es significativo observar cómo, frente a las estrategias narrativas frecuentemente apreciables en otras versiones remito a las observaciones de Zabala Gómez del Campo (191b-193b) sobre "el valor de la verdad"-, el término "leyenda" se emplea aquí para atenuar el grado de credibilidad atribuible al relato, lo que constata el planteamiento fluctuante de las narraciones legendarias, que se conceptualizan como un tipo de relato que gravita entre las categorías de lo histórico y lo ficcional (Dégh y Vázsonyi ${ }^{10}$ ). No es descartable, en este sentido, que el informante haya engarzado al final de su versión de la Llorona un motivo tomado de la leyenda de la autoestopista fantasma ${ }^{11}$. En cualquier caso, esta versión en la que el conductor se detiene para subir a la mujer en su coche se inicia con la narración del tipo A1 antes descrito, a lo que se añade el mencionado motivo de la mujer que atrae al conductor, asimilable al comienzo del tipo B1.

10 Sobre la "dinámica entre ficción e historia" en los relatos sobre la dama fantasma, remito a Palleiro (La dama fantasma).

$11 \quad$ Leddy recoge testimonios paralelos en Arizona: "A young Phoenician reports that 'La Lloronanita' appears on the Phoenix-Tucson highway on stormy nights, carrying a cradle, stopping cars, asking 'Where is my child?’” (“La Llorona in Southern” 275). 


\section{LA MUJER DE BLANCO}

Otra de las figuras femeninas fantasmales a la que a veces se asemeja la Llorona es la mujer de blanco, que encontramos representada en países como México, Nicaragua, Honduras y Uruguay. Su elemento más distintivo es la imagen de contraste sugerida por el vestido blanco con el que deambula en mitad de la noche. La apariencia fantasmal queda reforzada por su ingravidez y la ocultación de su rostro. Así, en los relatos de Nicaragua se afirma que la caminante "no pone los pies en el suelo" y "nunca enseña su rostro" (Pedrosa, Literatura oral n. $\left.{ }^{\circ} 126\right)$. De igual modo, circulan leyendas mexicanas que recogen estos mismos rasgos, como se aprecia en esta muestra de Xalapa (Veracruz, México): "él la quiso ver, pero la chica no dejó ver su rostro. Entonces el señor siguió avanzando y en algún momento oyó un gritó. Y al momento él se asustó y volteó para atrás, y vio cómo la chica se elevó, toda vestida de blanco, se elevó y comenzó a seguirlo más rápido" (Guillén Ortiz 263). De modo análogo, se documentan relatos uruguayos en los que la mujer de blanco se aparece en la oscuridad y desaparece cuando el lugar se ilumina: "Y dice que, de debajo de ese perro, salió una mujer toda de blanco... Y a mi madre le dio tanto miedo, tanto miedo, que disparó para arriba de la camioneta. Cuando arrancaron la camioneta y prendieron la luz, esa de blanco no estaba más" (Vigna Vilches 70). Se trata de un motivo aplicado con frecuencia a las figuras fantasmales, como es el caso de los relatos sobre la Llorona de Arizona que ya he mencionado (Leddy, "La Llorona in Southern" 273).

En el caso de esta leyenda, el encuentro con los paseantes nocturnos forma parte indisociable del relato, que finaliza describiendo las consecuencias dañinas sufridas por estos, quienes "quedan en estado de chock" (Pedrosa, Literatura oral n. ${ }^{\circ}$ 126). En algunas versiones, como la ya mencionada de Xalapa, las secuelas del encuentro se producen cuando el espíritu deja de ocultar su rosto y muestra sus rasgos desfigurados, tras lo cual "el señor [...] empezó a tener problemas de salud y nunca se pudo recuperar" (Guillén Ortiz 263).

$\mathrm{Al}$ igual que se observa en relación con la figura de la Llorona, algunas versiones sobre la mujer de blanco presentan motivos compartidos con la leyenda de la autoestopista fantasma y la de la mujer "cara de mula", a las que me referiré más adelante. Es el caso de este testimonio de Coatepec (Veracruz, México): "Sí, la han seguido, mucha gente todavía. Actualmente, los taxistas que luego quieren... que "ah, que se ve muy guapa", el cuerpazo y todo, y dicen que cuando voltea, es la cara de una mula. Sí, entonces, cuando se espantan, vaya" (Guillén Ortiz 264). 
Existen algunas versiones en las que, de forma análoga al relato compuesto de la Llorona, se cuenta la prehistoria de la mujer de blanco. Así, en una de las muestras recogidas en la localidad mexicana de Coatepec, en la que se emplea el recurso del relato dentro del relato, una anciana cuenta que la mujer de blanco había tenido un novio que le sacó los ojos por celos, momento a partir del cual "en venganza, procuraba atraer a hombres que la siguieran hasta el panteón y ahí, nada más al mirarla, pues ya, acababa con ellos" (ibid.). Es de notar cómo en esta versión se alude a que la mujer cegada tiene "dos luces rojas" en sus cavidades oculares, motivo que se asemeja al de los ojos "de fuego" en las leyendas sobre perros espectrales, como el Cadejo (Martínez Reyes n. ${ }^{\circ}$ 91), o los caballos fantasmales (Pedrosa, Literatura oral n. ${ }^{\circ}$ 162).

En algunas muestras de la tradición hondureña, el vestido de la mujer de blanco se asocia al de boda: "me decían que ahí en el potrero aparecía una mujer vestida de blanco. Pero yo jamás les creí: más bien me reía de ellos. ¡Hasta que un día la vi! Estaba tendida en la puerta, vestida con un velo como el que usan las muchachas para casarse. Nunca sentí tanto miedo como ese día" (Martínez Reyes n. ${ }^{\circ}$ 328). Se trata de un tópico aplicado a otras mujeres fantasmales como la Llorona (Horcasitas Pimentel 64; Sánchez Galicia 77) y la Sucia (Martínez Reyes n. ${ }^{\circ} 434$ ), de la que paso a ocuparme seguidamente.

\section{LA CIGUANABA, LA SUCIA Y LA CEGUA. VARIANTES DE UN PROTOTIPO FEMENINO}

En las leyendas sobre mujeres fantasmales de la tradición oral hispánica, circulan múltiples figuras con rasgos compartidos, al tiempo que estas presentan elementos distintivos que les confieren una entidad propia. Sin embargo, si analizamos un repertorio amplio y representativo de las distintas áreas folclóricas, observamos que determinados personajes asumen un mismo patrón caracterológico, además de compartir una serie de tipos narrativos. Este es el caso de la Ciguanaba, la Sucia y la Cegua (también denominada Segua o Tzegua), que, según trataré seguidamente, constituyen una misma figura desde el punto de vista tipológico ${ }^{12}$, si bien no procede asimilarlas, según veremos, al mismo prototipo de la Llorona.

12 Es de notar, por otro lado, cómo los propios transmisores señalan correspondencias entre dos de estas figuras: "existe La Sucia que es la misma Ciguanaba", en palabras de un 
En la tradición hondureña, encontramos representada a la Sucia como un espectro, "vestida de blanco, con el pelo largo, para enfrente de la cara, bañándose" (Martínez Reyes n. ${ }^{\circ} 16$ ), que destaca por su enorme atractivo: “es una mujer bonita, espectáculo de mujer" (Martínez Reyes n. ${ }^{\circ} 292$ ). Estos mismos elementos caracterizadores los encontramos aplicados en las descripciones de la Ciguanaba: "Desde lejos parece una mujerona, hermosa. Aparece normalmente bañándose en río o en una quebrada, generalmente a la medianoche. Cuando el hombre la mira, se vuelve inmediatamente loco por ella. Ella lo llama y lo atrae con su cuerpazo" (Martínez Reyes n. ${ }^{\circ} 444$ ). De la Cegua también se cuenta que "es una mujer muy guapa que persigue a los hombres mujeriegos" (Martínez Reyes n. ${ }^{\circ} 289$ ) y se la describe con "cabellera larga" y "arrodillada lavando [a orillas del río]" (Pedrosa, Literatura oral n. ${ }^{\circ}$ 144). La identificación del personaje con la figura de la lavandera fantasmal la encontramos explícitamente en algunos relatos sobre la Sucia: "justo por donde tenía que cruzar una quebrada, vio a una mujer lavando su ropa [...]. A ella se le conoce como La Sucia porque ella siempre está lavando ropa sucia" (Martínez Reyes n. ${ }^{\circ} 438$ ).

Uno de los tipos narrativos más recurrentes se articula en torno al motivo inicial de la mujer fantasmal que oculta el rostro con su pelo, hasta que, en un determinado momento, se gira repentinamente para espantar a quienes se aproximan: “¡Esa era La Sucia! Con el pelo para abajo. Y los volteó a ver y con los ojos bien amarillos, bien feos" (Martínez Reyes n. $\left.{ }^{\circ} 17\right)$. Esta imagen se introduce habitualmente en los relatos en los que la mujer se propone escarmentar a los mujeriegos a los que previamente seduce. Así pasa, por ejemplo, en una muestra de Copán Ruinas (Honduras) en la que un individuo sigue a la Sucia hasta un lugar oscuro sin ver su rostro, pues "solo lo llamaba por atrás, nunca le daba su rostro, sino que lo llamaba de espaldas", tras lo cual "él pues ahí la abrazó y la piquió ['besó en la boca'] y todo. Y cuando él le descubrió su pelo de la cara: miró que era toda desfigurada. Y dicen que el señor quedó como loco" (Martínez Reyes n. ${ }^{\circ} 18$ ).

El mismo esquema narrativo lo encontramos aplicado a la Ciguanaba en otro relato hondureño en el que un individuo se interesa por una mujer que: "se pasaba para delante y para atrás del caballo, y [...] en ningún momento

informante de la localidad hondureña de Yuscarán (Martínez Reyes n..$^{2}$ 282). Otro de Tatumbla (Honduras) afirma: “Antes sí la oía la gente a La Sucia. El nombre es Ciguanaba” (Martínez Reyes n. $\left.{ }^{\circ} 293\right)$. 
le daba la cara. No lo dejaba verle la cara", hasta que "se inclina mi abuelo en el caballo para darle el beso, le aparta el pelo de la cara y va viendo aquella mujer horrible, llena de gusanos con los ojos salidos. Mi abuelo dice que salió despavorido, y el caballo despicado" (Martínez Reyes n. ${ }^{\circ}$ 287). De modo análogo, tras los preliminares de la seducción, la Ciguanaba se muestra con la imagen de una bestia en este relato guatemalteco: "cuando [la Ciguanaba] ya está cerca, al alcance de la chica, se da cuenta de que la chica no es tan bonita, que tiene pies de caballo, o cara de caballo. Los pies los tiene volteados, al revés" (Pedrosa, Cuentos 55).

Idénticos elementos se introducen en los relatos atribuidos a la Cegua, como podemos comprobar en una versión de Santa Rosa (Copán, Honduras), en la que el personaje se describe como "mujer muy guapa que persigue a los hombres mujeriegos y pícaros" y que "no lo deja [al hombre] verle la cara", hasta que "se le transforma la cara como una calavera de caballo. Los ojos se le vuelven chibolas de fuego, y los dientes se le ponen como hachas", de modo que "el caballo se echa a correr, y así las víctimas no pueden bajarse del caballo tan fácil" (Martínez Reyes n. ${ }^{\circ} 289$ ). En cuanto al motivo de la ocultación de la cara con el pelo, no faltan tampoco muestras relativas a la Cegua, quien se presenta al comienzo de los relatos "con el cabello tirado hacia adelante para no mostrar el rostro" (Pedrosa, Literatura oral n. ${ }^{\circ} 143$ ). Estamos, por tanto, ante un tipo narrativo en el que la mujer fantasmal se representa y actúa del mismo modo ${ }^{13}$.

Los movimientos de estas mujeres fantasmales pueden ser desconcertantes. Según algunos testimonios sobre la Cegua: "Se le bailaba de un lado a otro, se le aparecía adelante y atrás" (Pedrosa, Literatura oral n. $\left.{ }^{\circ} 142\right)$, mientras que otros afirman que "si uno volvía a ver hacia atrás, esta se le aparecía adelante" (Pedrosa, Literatura oral n. $\left.^{\circ} 144\right)$. Algo similar se cuenta en este otro relato sobre la Ciguanaba: "él miraba que aquella mujer se pasaba para delante y para atrás del caballo, y él ni sentía a qué hora. La mujer así se la pasó todo el camino, cambie que cambie de puesto" (Martínez Reyes n. ${ }^{\circ}$ 287). Estos mismos cambios de posición, con los que quedan frustradas las expectativas sexuales del protagonista del relato, se atribuyen a la Sucia en

13 Circulan, no obstante, algunos relatos en los que se describe a la Cegua de forma genérica, como un colectivo de "mujeres vagas, que buscaban los maridos de otras" y en ocasiones agreden a sus esposas, como en esta versión nicaragüense: "la Cegua que era la amante de su esposo le cortó el pelo, y le llenó la cabeza de caca de cerdo" (Pedrosa, Literatura oral . $\left.^{\circ} 145\right)$. 
esta otra muestra de procedencia hondureña: "Dice mi papá que cuando él decía a abrazarla: se le pasaba para el otro [lado] y así y así. Y nunca, nunca, pudo abrazarla, ni besarla ni nada, porque, cuando decía hacerlo, se le pasaba para el otro lado" (Martínez Reyes n. ${ }^{\circ}$ 355). Por lo demás, este es un motivo recurrente, que encontramos también en algunas versiones hondureñas sobre carros fantasmales, cuyos desplazamientos son percibidos de modo similar (Martínez Reyes n. ${ }^{\circ}$ 78).

Otro motivo compartido por los relatos sobre esta figura, articulado en torno a frases formularias, es la agresiva provocación que la mujer hace a sus víctimas al reiterar la expresión: “¡Toma tu teta! ¡Toma tu teta!”, con variantes como “¡Tomá tu teta, jodido! ¡Tomá tu teta, cabrón!”, que encontramos indistintamente en boca de la Sucia en la tradición hondureña (Martínez Reyes n. 294 y 437, respectivamente) y de la Cegua en la nicaragüense, quien exclama: "Tomá tu teta, que estás con hambre" (Pedrosa, Literatura oral n. $\left.{ }^{\circ} 143\right)$.

En algunas versiones, se advierte del riesgo de enloquecer al que se exponen quienes se atrevan a mirar el rostro de la Cegua (Pedrosa, Literatura oral n. ${ }^{\circ}$ 144), al igual que se cuenta de los hombres que se acerquen a la Sucia: “¡Él se quedó trastornado! Y él sentía que tenía el agua hasta el cuello pues y no era nada, en lo sequito lo estaba ahogando. Pero como la misma loquera..." (Martínez Reyes n. ${ }^{\circ}$ 295). Las consecuencias son las mismas en los relatos dedicados a la Ciguanaba: "Y lo fueron hallar, estaba echando espuma. Estaba vivo todavía, pero quedó loco. [...] ¡Era la Ciguanaba! La que le dicen la Ciguanaba que se estaba riendo de él y aquel maje ya no podía hablar, se quedó traumado y por eso no les pudo decir a los demás" (Martínez Reyes n. ${ }^{\circ}$ 443).

Entre las acciones atribuidas a estas mujeres fantasmales están los intentos de robar niños a las madres, quienes se enfrentan a la situación mediante oraciones: "La mujer cuando ella empezó a orar, se le acercó [la Sucia], a jalarle al niño de los pieses. Y le decía que se lo iba a llevar, que se lo iba a llevar" (Martínez Reyes n. $\left.{ }^{\circ} 16\right)$. De igual modo, la Ciguanaba también está caracterizada como raptora de niños en la tradición hondureña: "Entonces [la madre] acostó la niña más tierna en una hamaca y se fue a traer agua al vertiente. Y dejó a la niña más grande, meciendo a la niña más pequeña. En lo que ella andaba trayendo agua: llegó la Ciguanaba en forma de la mamá. Y se llevó la niña más grande" (Martínez Reyes n. ${ }^{\circ} 442$ ).

La condición diabólica de la Cegua queda de manifiesto en algunos relatos en los que se intenta alejar su presencia mediante ritos destinados a expulsar 
demonios, como en esta muestra de Nicaragua: "Entonces la madre [...] se fue al lugar donde le había salido la Cegua a sus hijos, y les untó ajos a los árboles en forma de cruz, y les echó agua bendita. Y rezó una oración al señor, para que no volvieran a salirle a sus hijos en el campo de las siembras" (Pedrosa, Literatura oral n. ${ }^{\circ} 143$ ). Es destacable, a este propósito, cómo en uno de los relatos hondureños sobre la Sucia, se alude expresamente a que esta "hizo un pacto con el Diablo y le entregó el corazón” (Martínez Reyes n. ${ }^{\circ} 433$ ).

Por último, está el motivo de la mujer fantasmal que adopta la identidad de la esposa (Martínez Reyes n. ${ }^{\circ}$ 296) o la novia de su víctima: "En las quebradas, a las doce, por ejemplo, yo tengo mi novia y ella [La Sucia] se hace [de] la forma de mi novia, de noche ¿me entiende? En un callejón se hace [de] la forma. A veces uno va en la bicicleta: se le monta. Bien allá; pero ella no da la cara, ella no da la cara, solo el cuerpo de la novia de uno" (Martínez Reyes n. $\left.{ }^{\circ} 298\right)$, motivo que también es asimilado por algunas leyendas sobre la Llorona (Martínez Reyes n. ${ }^{\circ} 320$ ), si bien no lo he encontrado aplicado a la Ciguanaba ni a la Cegua.

$\mathrm{Al}$ igual que sucede con la leyenda de la Llorona, el personaje que nos ocupa es objeto de relatos centrados en el pasado, como un modo de justificar su comportamiento después de muerta. El motivo de la venganza adquiere un claro protagonismo narrativo: "Fue que [a] ella la engañaron. [La Sucia] tenía esposo y el marido le fue infiel. Entonces ella parece que se mató. Y decidió hacer eso: a todos los hombres infieles hacerles daño" (Martínez Reyes n. ${ }^{\circ}$ 292). La frustración amorosa de la Sucia, que también puede deberse a la deshonra y el abandono por parte del novio (Martínez Reyes n. ${ }^{\circ} 433$ ), queda patente en otro inquietante relato hondureño, en el que se equiparan los nombres del personaje: "La Sucia o la Ciguanaba se supone que fue que la encantó una... ella se iba a casar. Era una muchacha que se iba a casar y entonces una señora le perdió los anillos. Y se quedó ella buscando. Se trastornó y quedó buscando el anillo siempre ella, como en los ríos" (Martínez Reyes $\mathrm{n}^{\circ}{ }^{\circ}$ 297). La misma situación está en el fondo de otro de los relatos, en el que la Sucia se muestra incapaz de quitarse el vestido de novia pese a la imposibilidad de que la boda se celebre debido al ahogamiento del novio: "La muchacha salió loca, con su vestido blanco al río a buscar al novio. Pero nunca lo lograron encontrar. Esa mujer enloqueció de la tristeza. Nunca se quitó el vestido blanco hasta que se murió" (Martínez Reyes n. ${ }^{\circ} 434$ ).

A la vista de este conjunto de relatos, cabe considerar a la Sucia, la Ciguanaba y la Cegua como manifestaciones de un mismo prototipo o matriz de mujer fantasmal, que encontramos representada con iguales rasgos caracterológicos 
y que, asimismo, interviene en una serie de relatos con entidad propia dentro del conjunto de las narraciones protagonizadas por espectros femeninos.

\section{OTROS PROTOTIPOS ESPECTRALES FEMENINOS}

Resultaría imposible esbozar aquí un panorama de las restantes formas adoptadas por las mujeres fantasmales, que en ocasiones asumen incluso la identidad de personas conocidas, como Rufina Cambaceres, Frederike von Grottes o Beatrice di Canossa, sobre las que circulan relatos tanto en los medios orales como virtuales, con la consecuente multiplicidad y dispersión de rasgos caracterológicos (Palleiro, "La dama fantasma en sus distintos nombres"; Palleiro, La dama fantasma). Me detendré, por tanto, una vez analizado el prototipo representado por la Llorona y la Ciguanaba (con sus distintos nombres e identidades), en algunas figuras recurrentes de la tradición hispánica. En particular, mencionaré aquellos personajes que comparten motivos con las figuras ya examinadas.

Además de las figuras localizadas en espacios que se rehúye visitar, a las que sencillamente se invoca como "encantadas", sin precisar apenas sus rasgos definitorios ${ }^{14}$, existe un inabarcable repertorio de leyendas cuyo desarrollo narrativo se reduce a la simple descripción del espectro y la reacción de miedo que suscita. Sirvan como ejemplo, entre tantos otros, los relatos de la tradición gitana almeriense, en España, sobre fantasmas que peinan su cabello rubio junto a un lavadero del que las mujeres huyen a una determinada hora en la que se produce la aparición (Gómez et al. n. ${ }^{\circ}$ 19, 20 y 21).

En la tradición colombiana, se difunden leyendas sobre la Muelona, caracterizada como una mujer fantasmal que se comporta de modo análogo a la Ciguanaba, con la diferencia de que aquella devora a sus víctimas. Según un relato registrado en Bogotá (Colombia), se trata de una mujer de origen español con dotes adivinatorias que fue asesinada en venganza por

14 Remito al siguiente testimonio documentado en Arroyo Frío (Cazorla, España): "Lo que sí hablaban es de que 'no subir por, por, por aquel sitio porque allí hay una encantá, hay una persona que encanta a las personas'. De hecho, aquí en el sitio que se llama la parte esta de la derecha de Arroyo Frío, 'El Toril', eh, era por esa zona. Si no me equivoco, decían que había una encantá. Y nada, nadie subía por ahí. No sé por qué motivo, pues... la gente no quería que subiéramos por ahí o lo que sea [...] No sé, como que te asustaban con aquello y ya no sé si sería verdad, no sería verdad...” (Mañero Lozano 0732n). 
el daño provocado a muchas personas. Tras esto, su fantasma se aparece a "los hombres que eran viciosos y jugadores" para seducirlos y devorarlos con unos "dientes afilados como los de una bestia" (Martínez Reyes 609)1 .

La mujer "cara de mula" adquiere entidad propia en otro relato legendario con cierta complejidad, en tanto que, al igual que en las versiones compuestas de la Llorona, contiene una historia cerrada y sus consecuencias posteriores. Según cuenta una informante de Nagarote (León, Nicaragua), una mujer se avergonzaba del aspecto físico y la pobreza de su madre, hasta el punto de fingir que no estaba en casa cuando recibía su visita. Cierto día en que ambas se encuentran, la hija busca una falsa excusa para negarle el alimento a su madre. A partir de este momento, se produce una brutal transformación: "conforme iban pasando los días le iban saliendo casquitos, tanto en las manos como en los pies, pelos de bestia en todo el cuerpo. La cara se le transformaba en cara de caballo, las orejas como si tal fueran de mulas, le salió rabo o cola, gruñía como mula" (Pedrosa, Literatura oral n. ${ }^{\circ}$ 127). Desde este momento, la mujer vaga continuamente buscando sin éxito a su madre para suplicarle el perdón, sin obtener tampoco la ayuda de quienes se cruzan en su camino, que huyen despavoridos debido a su aspecto animal. Pues bien, el motivo de la metamorfosis se propaga a otras narraciones relacionadas que lo incorporan, como sucede en la leyenda de la Llorona, que adquiere esta apariencia animal en algunas versiones mexicanas (Guillén Ortiz 259-261), lo que señala correspondencias en distintas áreas de Hispanoamérica ${ }^{16}$ (Robe 48). Existen asimismo figuras fantasmales como la Chola Encarnada, conocida en la tradición boliviana, que provoca la muerte a quienes le niegan la comida (Martínez Reyes 612-613). Reparemos, por otra parte, en las correspondencias entre esta leyenda de la mujer "cara de mula" y el tipo cuentístico "El castigo de una

15 Martínez Reyes recoge también relatos sobre otra mujer fantasmal de la tradición colombiana, la Pata Sola, que persigue a los hombres que dañan a las mujeres; y sobre el personaje boliviano de la Viudita, quien, después de asesinar a su esposo por haberle sido infiel, persigue a los hombres ebrios e infieles para llevarlos hasta el cementerio y tomar nueva venganza (610-611).

16 Las confusiones a las que me he referido se ven intensificadas debido a la variedad de nombres que le se atribuyen a este y otros motivos legendarios. Según indica Robe: "there is wide variety in the names by which the phantom woman is known. The following examples will illustrate: Guatemala, la llorona; Honduras, la sucia; Salvador, la ciguanaba; Nicaragua and Costa Rica, la cegua; Venezuela, la dientona; Bolivia and Chile, la vieja" (113-114). 
mujer mala" (ATU 750C) ${ }^{17}$, en el que la falta de hospitalidad de una mujer es castigada con su transformación en vaca.

Las lavanderas también son descritas como almas en pena en tradiciones muy diversas. En Nicaragua se cuenta la leyenda de la Moncha Tustusa, "mujer alta de pelo largo, rubio -por eso el nombre de Tusa-" a quien se le ahoga el hijo mientras está lavando en su compañía, tras lo cual el fantasma de ella es visto junto al río con apariencia de lavandera (Pedrosa, Literatura oral n. ${ }^{\circ}$ 123). Según la tradición catalana, la corriente de los ríos arrastra el alma de las lavanderas que han incumplido la norma de no trabajar durante el Viernes Santo; y, en Galicia, se caracteriza también como lavanderas a los fantasmas de las madres muertas en el parto o a las que pierden a sus hijos sin bautizar (Martín Sánchez 405).

Otra de las mujeres en pena con entidad propia y que al mismo tiempo comparte motivos con las anteriores es la autoestopista fantasma, a la que se han dedicado importantes investigaciones desde el estudio pionero de Brunvand ${ }^{18}$. Las leyendas cuentan que los conductores suben en el asiento de atrás de sus vehículos a una mujer que desaparece misteriosamente en el momento en que estos vuelven atrás la cabeza. Sirva como ejemplo este relato hondureño sobre la mujer fantasmal que aparece en la cuesta de la Moramulca, situada en la carretera Panamericana, donde se recurre al motivo de la apariencia incorpórea: "A mitad del camino, no es que la mujer desaparece de la nada. Cuando el hombre este mira por los espejos, mira que la mujer estaba parada a un lado de la carretera. El hombre frenó de un solo y la mujer comenzó a desvanecerse en el aire" (Martínez Reyes n. ${ }^{\circ}$ 246). Se dan también casos en los que la autoestopista aparece sentada en el coche sin que el conductor la haya subido consigo: "Decía él que no sabe ni cómo metió todo el acelerador, $\mathrm{y}$ en ese mismo momento vio que, en el asiento del pasajero, iba la mujer. Contaba que él [que] solo sintió una tufancina ['mal olor'] a carne podrida, y que todo se le puso negro. Ese hombre tuvo un accidente tan horrible, que por gracia divina la está contando vivo" (Martínez Reyes n. ${ }^{\circ} 251$ ).

17

La sigla "ATU” remite al sistema Aarne-Thompson-Uther de clasificación de fábulas y cuentos de hadas.

18 Remito también a los acercamientos a la tradición francesa (Campion-Vincent) y española (Pedrosa, Cuentos 34-79). De especial interés son asimismo las aportaciones metodológicas y las versiones de esta leyenda documentadas por los responsables de la plataforma The RumorFolk Database (http://rumorfolk.arxiudefolklore.cat). Véase al respecto las investigaciones de Oriol Carazo y Samper Prunera. 
Una de las figuras folclóricas próximas a este espectro es la Viuda, que se aparece a los conductores, particularmente a aquellos que trasnochan sin la compañía de su esposa, al igual que las víctimas de otros fantasmas como la Sucia: "ahí estaba una mujer horrible sentada a su lado, que le empezó a decir cosas para enamorarlo. Dice mi abuelo que él aceleró lo más que pudo, cerró los ojos y rezó un padre nuestro. Cuando revisó de nuevo, la mujer ya no estaba [...] y le dijeron que eso que él vio fue una viuda que asusta a los recién casados que dejan a sus mujeres por la parranda" (Martínez Reyes n. ${ }^{\circ} 319$ ).

El motivo es aún más desagradable en los relatos sobre la Descarnada, autoestopista fantasmal que "se comporta normal. Pero a mitad de camino ella se comienza a desvestir, y luego se comienza a quitar la carne y arrancarse los pellejos. Los hombres queden mudos del miedo y muchos hasta se han accidentado" (Martínez Reyes n. ${ }^{\circ}$ 285). En algunas versiones compuestas, se recoge la prehistoria de la mujer, de quien se cuenta que fue asesinada por un novio por un ataque de celos (Guillén Ortiz: 254), o que se suicidó en la carretera tras ser abandonada el día de su boda (Martínez Reyes n. ${ }^{\circ} 249$ ), entre otras circunstancias trágicas.

Circulan, por otro lado, relatos que describen solamente la aparición de una mujer fantasmal en la carretera, sin que se añada el motivo del conductor que la sube al coche: "se nos cruzó enfrente del carro una gran luz de la nada. Cuando volteamos a ver, vimos una mujer vestida de blanco. Estaba iluminada y se miraba medio borrosa por tanta luz que la alumbraba", a lo que se añade en esta muestra hondureña la explicación del motivo de su muerte: "[Un trabajador de una gasolinera] nos contó que ese espectro es de una mujer que murió en un accidente de carro. Nos contó que ella iba con su familia en un carro y se dieron vuelta. Dice el señor que solo ella murió" (Martínez Reyes n. ${ }^{\circ}$ 247). Este tipo de apariciones se caracterizan como seres malignos en muchos de los relatos, como en esta muestra también procedente de Honduras: "Cuando alguien va solo conduciendo en dirección de bajada, es cuando el conductor voltea a ver el retrovisor, y es justo en ese mismísimo momento en que aparece la mujer. Ese fantasma ha provocado cualquier cantidad de accidentes ahí. Los conductores pierden el control y se accidentan" (Martínez Reyes n. ${ }^{\circ}$ 248).

El mismo contexto sirve de marco para algunas leyendas sobre la Taconuda narradas en Honduras. Según el testimonio de una informante de Tegucigalpa, se trata de la novia de un conductor de autobuses que falleció al chocar el vehículo con un taxi. Desde entonces, su espectro vaga por las calles en busca de taxistas de quienes tomar venganza: "cuando los taxistas 
la montan, la miran, y ya después cuando ellos voltean así a ver atrás para cobrarle el pasaje: ya no está. ¡Y no hace bulla ni nada para salir! Y dice que cuando ellos voltean a ver para atrás, ella ya está con un puñal y se los mete a ellos y los mata. Dicen que ya ha matado como a cuatro taxistas" (Martínez Reyes n. ${ }^{\circ} 81$ ). En otros relatos hondureños se la describe como el fantasma de una mujer con grandes tacones que fue asesinada en la calle por un individuo que intentó abusar de ella (Martínez Reyes n. ${ }^{\circ}$ 108). Al igual que en ciertas versiones de la Llorona (Guillén Ortiz 143-144), esta figura se asocia también al motivo de la percepción contradictoria de la sensación de peligro y la proximidad del sonido: "Dicen también que, cuando los pasos se escuchan cerca, es que la Taconuda ya va lejos. Pero que, si los pasos se escuchaban lejos, es que se acerca" (Martínez Reyes n. ${ }^{\circ} 109$ ).

\section{CONCLUSIONES}

Según se desprende del análisis de las versiones de la Llorona difundidas en las distintas áreas geográficas, los motivos folclóricos representados en estas permiten identificar cuatro tipos narrativos asociados a un primer segmento temporal que se corresponde con los sucesos previos e inmediatamente posteriores a la muerte del personaje. Estos cuatro tipos podrían caracterizarse del siguiente modo: A1) la pérdida de los hijos de la Llorona se atribuye a causas accidentales; A2) los hijos de la Llorona son asesinados por su esposo u otro hombre; A3) la Llorona mata a sus hijos movida por el despecho amoroso hacia el padre de estos; y A4) la Llorona abandona a sus hijos por desapego afectivo o enajenación mental.

En cuanto a los relatos que, con posterioridad a la muerte de la Llorona, describen los encuentros de esta con otros individuos, las muestras analizadas se articulan a partir de dos tipos diferentes: B1) la Llorona atrae a un individuo a quien provoca la muerte o algún tipo de daño o perturbación; y B2) la Llorona sufre las consecuencias negativas del encuentro con los vivos. Como he puesto también de manifiesto, este segundo segmento temporal presenta varios motivos compartidos con las narraciones protagonizadas por otras mujeres espectrales.

Concluimos asimismo que los personajes de la Sucia, la Ciguanaba y la Cegua constituyen una misma figura legendaria con una entidad propia y diferenciada respecto de la Llorona. A la vista de las versiones analizadas, podría afirmarse que, en términos generales, la maternidad truncada constituye 
un marcador específico de la Llorona, que representa una tipología en la que el espectro femenino y su llanto son representativos de la culpa y la expiación por el descuido, la pérdida o el asesinato de sus hijos. Por otro lado, la figura representada por la Sucia, la Ciguanaba o la Cegua tiende a asociarse con el castigo o la censura de acciones masculinas percibidas como reprobables, generalmente atribuidas a individuos trasnochadores, infieles o bebedores. En determinadas ocasiones, esta figura se comporta como raptora o agresora de niños, rasgo a veces también atribuido a la Llorona. En efecto, las distintas figuras comparten un buen número de motivos folclóricos, a su vez asociados a otros espectros femeninos. No ha sido nuestro objetivo, con todo, estudiar la configuración tipológica de estas otras leyendas, materia a la que convendría dedicar futuros estudios que nos permitan avanzar en el conocimiento de los distintos ciclos legendarios.

\section{BIBLIOGRAFÍA}

Aragón, Ray John de. The legend of La Llorona. Las Vegas, Sunstone Press, 1980.

Badillo Gómez, Gabriela SAmia. "La mujer que busca a sus hijos; la mujer que desbarranca a los hombres: caracterización del personaje de la Llorona en algunas comunidades del centro sur del estado de Puebla". Los habitantes del encanto. Seres extraordinarios en comunidades indígenas de América. Claudia Rocha y Claudia Carranza (coord.), San Luis de Potosí, El Colegio de San Luis, 2015, pp. 91-106.

Boggs, Ralph S. "Mapa preliminar de las versiones folklóricas de México". Folklore Americas 9, 1949, pp. 1-4.

Butterworth, Douglas y Fernando Horcasitas. “La Llorona”. Tlalocan: Revista de Fuentes para el Conocimiento de las Culturas Indígenas de México 4, N³, 1963, pp. 204-224.

Brunvand, Jan Harold. The Vanishing Hitchhiker: American Urban Legends and Their Meanings. Nueva York y Londres, W. W. Norton \& Company, 1981.

Caballero, María del Socorro. Narraciones tradicionales del Estado de México. 2. ${ }^{\text {a }}$ ed. Toluca, Imagen, 1994.

Campion-Vincent, Véronique y Jean-Bruno Renard. Légendes urbanes. Rumeurs d'aujourd'hui. París, Payot and Rivages (Petite Bibliothèque Payot), 1998.

Dégh, Linda y Andrew VÁzsonyi. "Legend and belief”. Folklore Genres. Dan Ben-Amos (ed.), Austin, University of Texas Press, 1976, pp. 93-123

Espinosa, Aurelio M. "New Mexican Spanish Folklore". Journal of American Folklore 23, $\mathrm{N}^{\circ} 90,1910$, pp. 395-418.

Gómez, Nieves, Yolanda Guirao, Desirée Rojo, Juan José Rodríguez y José Manuel Pedrosa. Gitanos que andan con la luna. Literatura tradicional de los gitanos de Almería. Almería, Instituto de Estudios Almerienses, 2007. 
González Manrique, Manuel Jesús. "El estigma de Eva en la leyenda mexicana La Llorona.

Su representación cinematográfica". Revista de Antropología Experimental 13, 2013, pp. 541-556.

Granados, Berenice. "Xtabay y la Llorona: vestigios de entidades k'uyel mesoamericanas en la narrativa de tradición oral". Variación regional en la narrativa tradicional de México. Aurelio González, Nieves Rodríguez Valle y Mercedes Zavala Gómez del Campo (eds.), Ciudad de México / San Luis de Potosí, El Colegio de México / El Colegio de San Luis, México, 2013, pp. 133-142

Guillén Ortiz, Adriana. Personajes y espacios sobrenaturales en la tradición oral de Coatepec,

Veracruz. Tesis de Maestría, San Luis Potosí, Colegio de San Luis, 2016.

Hawes, Bess-Lomax. "La Llorona in Juvenile Hall”. Western Folklore 27, º3, 1968, pp. 153-170.

Horcasitas Pimentel, Fernando. "Textos modernos de la Llorona". Notas Mesoamericanas 1, 1950, pp. 34-67.

Kirtley, Bacil F. “La Llorona and Related Themes”. Western Folklore 19, №3, 1960, pp. 155-168.

Lara Figueroa, Celso A. Viejas leyendas de Guatemala vueltas a contar. Ciudad de Guatemala, Dirección General de Antropología e Historia, 1980.

Leddy, Betty. "La Llorona in Southern Arizona”. Western Folklore 7, N³, 1948, pp. 272-277. “La Llorona Again”. Western Folklore 9, N4, 1950, pp. 363-365.

Lizano H., Víctor. Leyendas de Costa Rica. San José, Costa Rica, Soley y Valverde, 1941.

Mañero Lozano, David (dir./ed.). Corpus de Literatura Oral. 2. ${ }^{a}$ ed. Jaén, Universidad de Jaén, 2019. <https://corpusdeliteraturaoral.ujaen.es/> [12-2-2020].

Martínez Reyes, Fernanda María. La narrativa oral en Honduras: nuevas exploraciones en los inicios del siglo XXI. Tesis doctoral. Alcalá de Henares, Universidad de Alcalá, 2016.

Miller, Elaine K. Mexican Folk Narrative from the Los Angeles Area. Legendary Narratives. Austin, The University of Texas Press / American Folklore Society, 1973.

Oriol Carazo, Carme y Emili Samper Prunera. "Rumours and contemporary legends today: The Vanishing Hitchhiker in RumorFolk database". Estudios de Literatura Oral Popular 5, 2016, pp. 71-83. DOI: 10.17345/elop201671-83

Palleiro, María InÉs. "La dama fantasma y el monstruo del lago. Narración, ciencia y creencia en actuaciones discursivas". RUNA 32, N², 2011, pp. 145-162.

"La dama fantasma en sus distintos nombres: de Rufina Cambaceres a Beatrice di Canossa". Rumbos del hispanismo en el umbral del Cincuentenario de la AIH. vol. VI. Patrizia Botta (coord). Roma, Bagatto Libri Coord., Hispanoamérica, eds. Stefano Tedeschi y Sergio Botta, 2012. 46-57.

La dama fantasma. Los laberintos de la memoria en el relato folklórico. Buenos Aires, La bicicleta ediciones, 2018.

Pedrosa, José Manuel. La autoestopista fantasma y otras leyendas urbanas españolas. Madrid, Páginas de Espuma, 2004.

Cuentos y leyendas inmigrantes. Duendes, fantasmas, brujas, diablos, santos, bandidos, y otros seres inquietos e inquietantes de Hispanoamérica y de algún misterioso lugar más. Guadalajara, Palabras del Candil (Colección Tierra Oral, 2), 2008. 
Literatura oral en Nicaragua. León, Nicaragua / Alcalá de Henares: Editorial Universitaria, UNAN / Universidad de Alcalá, 2012.

Robe, Stanley L. Mexican Tales and Legends from Veracruz. Berkeley, University of California (Folklore Studies 23), 1971.

Sánchez Galicia, Alejandra (coord.). ¿Me lo cuentas otra vez? Ciudad de México, Mano Vuelta Editorial, 2019.

Thоmpson, Sтітн. Motif-index of folk-literature: a classification of narrative elements in folktales, ballads, myths, fables, mediaeval romances, exempla, fabliaux, jest-books, and local legends. Copenhague y Bloomington, Indiana University Press, 1955-1958.

UtHer, HANS-JÖRG. The Types of International Folktales. A Classification and Bibliography, Based on th System of Antti Aarne and Stith Thompson. Helsinki, Suomalainen Tiedeakatemia, Academia Scientiarum Fennica, 2004.

VAldÉs, Marisela. "En la mirada, en el oído. Narraciones tradicionales de la Llorona". Revista de Literaturas populares 2, N², 2002, pp. 139-157.

Vigna Vilches, SibILA. Etnografias extraordinarias: gentes, espiritus y asombros en Salto, Uruguay. Madrid, Consejo Superior de Investigaciones Científicas (Colección: Biblioteca de Antropología 61), 2020.

Zabala Gómez del Campo, Mercedes. “Apuntes acerca de la leyenda en la tradición oral del noreste de México”. Arrabal 1, 1998, pp. 191-195. 